\title{
Effect of Ultrasound Therapy in the management of Chronic Nonspecific Low Back Pain
}

\author{
Aparajeya Bivab Bikash Baral', Sohely Rahman², SM Mazharul Islam³, Bijoya Dey Happy, \\ Musa Muhammad Hojaifa ${ }^{5}$, Ripon Kumar Saha ${ }^{6}$, Palash Nag ${ }^{7}$
}

\begin{abstract}
${ }^{1}$ Assistant Professor, Department of Physical Medicine \& Rehabilitation, Dhaka Medical College Hospital, Dhaka Bangladesh; ${ }^{2}$ Professor \& Head, Department of Physical Medicine \& Rehabilitation, Dhaka Medical College Hospital, Dhaka, Bangladesh; ${ }^{3}$ Assistant Professor, Department of Physical Medicine \& Rehabilitation, Dhaka Medical College Hospital, Dhaka, Bangladesh;

${ }^{4}$ Assistant Professor, Department of Physical Medicine \& Rehabilitation, National institute of Neurosciences and Hospital, Dhaka, Bangladesh; ${ }^{5}$ Assistant Professor, Department of Physical Medicine \& Rehabilitation, Sher-E-Bangla Medical College, Barishal, Bangladesh; ${ }^{6}$ Assistant Professor, Department of Physical Medicine \& Rehabilitation, Dhaka Medical College Hospital, Dhaka Bangladesh; ${ }^{7}$ Medical Officer, Department of Physical Medicine \& Rehabilitation, Chattogram Medical College Hospital, Chattogram, Bangladesh
\end{abstract}

[Received on: 22 April 2021; Accepted on: 12 May 2021; Published: 1 July 2021]

\begin{abstract}
Background: Chronic non-specific low-back pain (NSLBP) has become one of the main causes of disability in the adult population around the world. Therapeutic ultrasound is frequently used by physiatrists in the treatment of LBP and is one of the most widely used electro-physical agents in clinical practice. Objective: To see the effects of ultrasound therapy (UST) in the patients with chronic nonspecific low back pain. Methodology: This randomized control trial was performed in the Department of Physical Medicine \& Rehabilitation of Dhaka Medical College Hospital during the period from December 2014 to May 2015. Patients presented with chronic nonspecific LBP in an age between 18 and 55 years of both sexes attending in the Department of Physical Medicine \& Rehabilitation at Dhaka Medical College Hospital, Dhaka were included as study population. A total of 80 patients presented with chronic nonspecific LBP who had fulfilled the selection criteria were taken as study population. They were divided into two groups named as treatment group (Group A) and control group (Group B). Each group had 40 patients. During follow up 8 patients (4 patients from each group) were lost. Final analysis was done with data collected from 72 patients. Patients of group A were given UST, NSAIDS, exercises and ADL instructions whereas patients of group B were given same treatment except UST. Result: In both groups female were predominant than male. Most of the patients were in $31-40$ years age group. Mostly housewives suffered from NSLBP. All patients were from either poor or middle-class family. Mean $( \pm \mathrm{SD})$ duration of pain was $11.3( \pm 12.5)$ months and $11.7( \pm 8.7)$ months in group A and group B respectively. Sedentary life style and repetitive lifting are the major risk factors in both groups. Character of pain was mostly dull in both groups, severity of pain was mostly moderate and relieving factor was mostly rest in both groups. Prolonged standing and prolonged sitting were the major aggravating factors in both groups. VAS and ODI were reduced gradually in both groups. Conclusion: Ultrasound therapy has a significant role in the management of chronic nonspecific low back pain. [Journal of National Institute of Neurosciences Bangladesh, July 2021;7(2):122-125]
\end{abstract}

Keywords: Chronic nonspecific; low back pain; ultrasound therapy

Correspondence: Dr. Aparajeya Bivab Bikash Baral, Assistant Professor, Department of Physical Medicine \& Rehabilitation, Dhaka Medical College Hospital, Dhaka, Bangladesh; Email: drbivab42@gmail.com; Cell no.: +8801717493018

Conflict of interest: There is no financial conflict of interest relevant to this paper to disclose.

Funding agency: This research project was not funded by any group or any institution.

Contribution to authors: Baral $\mathrm{ABB}$, Rahman $\mathrm{S}$ have contributed from the protocol preparation, data collection up to report writing. Manuscript writing has been performed by Islam SMM, Happy BD. Hojaifa MM, Saha RK, Nag P have revised the manuscript.

How to cite this article: Baral ABB, Rahman S, Islam SMM, Happy BD, Hojaifa MM, Saha RK, Nag P. Effect of Ultrasound Therapy in the management of Chronic Nonspecific Low Back Pain. J Natl Inst Neurosci Bangladesh, 2021;7(2): 122-125

Copyright: (C2021. Baral et al. Published by Journal of National Institute of Neurosciences Bangladesh. This article is published under the Creative Commons CC BY-NC License (https://creativecommons.org/licenses/by-nc/4.0/). This license permits use, distribution and reproduction in any medium, provided the original work is properly cited, and is not used for commercial purposes.

\section{Introduction}

Low back pain is defined as an uncomfortable sensation in the lumbar and buttock region originating from neurons near or around the spinal canal that are injured 
or irritated by one or more pathological process ${ }^{1}$. It affects the area between the lower rib cage and gluteal folds ${ }^{2}$. For the majority of patient with low back pain a specific diagnosis cannot be defined on the basis of anatomical or physiological abnormalities. Chronic Non-specific Low back pain refers to an episode of activity-limiting low back pain (with no pain referred into either lower limb) that lasts for 3 months or more ${ }^{3}$.

Chronic low back pain is very frequently found in our day to day practice ${ }^{4}$. Risk factors include heavy lifting, bending and twisting, bodily vibration, obesity, and poor conditioning, although low back pain is common even in people without these risk factors ${ }^{5}$. It is the most common reason that adults seek outpatient physical therapy ${ }^{6}$. Therapeutic ultrasound (US) is among the commonly used physical modalities for treating with soft tissue injuries? ${ }^{7}$. There is dearth of evidence for the clinical use of therapeutic US in patients with $\mathrm{LBP}^{8}$. In attempts to document treatment effectiveness the randomized clinical trial is regarded as most important scientific instrument?.

In Bangladesh, although many people in the community is suffering from nonspecific low back pain, a paucity of information exists regarding exact role of physiotherapeutic measures including ultrasound therapy (UST) in the management of chronic nonspecific low back pain. The incidence of nonspecific low back pain and its socioeconomic implications have led to the search for improved methods of management to reduce pain \& stiffness, improve mobility, optimize function \& hence they can contribute for their family, society, nation as well as themselves. So, this present study was undertaken to evaluate the effect of ultrasound therapy (UST) on pain \& functional performance in patients with chronic nonspecific low back pain.

\section{Methodology}

Study Population \& Settings: This was a randomized clinical trial. This study was carried out from December 2014 to May 2015 for a period of six (6) months. This study was conducted in the Department of Physical Medicine and Rehabilitation at Dhaka Medical College Hospital, Dhaka, Bangladesh. The patients having Chronic nonspecific LBP with the age between 18 and 55 years with both male and female were included as study population. Patients having inflammatory spondyloarthropathy, traumatic LBP, malignancy, cauda equina syndrome were excluded from study.

Randomization and Blinding: This was a single-blind study where individual patients were kept blinded. They were blinded to treatment allocation in groups. Patients were randomly divided in to two groups by the way of lottery. Group A was treatment group and Group B was control group.

Intervention: Patients in both groups were treated with same drugs (Tab. Ibuprofen $400 \mathrm{mg}$ thrice daily orally after meal for 2 weeks was prescribed to all patients of two groups with coverage of cap. Omeprazole $20 \mathrm{mg}$ twice daily before meal), same exercise was prescribed and same ADL was advocated. Furthermore, treatment group (group A) was treated with ultrasound therapy three times weekly for 4 weeks of a total of 12 sessions. Ultrasound treatment was administered for 10 minutes per session to the most tender area over low back region at a frequency of $1 \mathrm{MHZ}$ and an intensity of $1.5 \mathrm{~W} / \mathrm{cm} 2$, pulsed mode 1:4, with a transducer of $5 \mathrm{~cm} 2$ and with aquasonic gel. UST was given by the physiotherapists. Follow up \& Outcome Measures: The follow up of the all patients of both groups were done after 2 weeks, 4 weeks and 8 weeks from the first visit. The outcome of the study was to estimate the pain after giving the treatment. The pain was measured by VAS scale as well as by Oswestry disability index (ODI). Eight patients were dropped out (4 patients from each group) during follow up. Finally, 72 patients were found at the time of final follow up.

Statistical Analysis: Statistical analysis was performed with Statistical Packages for Social Sciences (SPSS-17) (SPSS Inc, Chicago, IL, USA). 95\% confidence limit was taken. All data were recorded systematically in preformed data collection Data was presented on a categorical scale compared between the groups using Chi-square (X2) or Fisher's Exact Probability test, while the data presented on a quantitative scale was compared between the groups using Student's ' $t$ ' test. For all analytical tests, a probability (p) value of $<0.05$ $(p<0.05)$ was considered statistically significant and $\mathrm{p}<0.01$ was considered highly significant but $\mathrm{p}>0.05$ was taken as non-significant.

\section{Results}

A total number of 72 nonspecific chronic LBP patients were recruited for this study of which 36 patients were in treatment group (group A) and the rest 36 patients were in the control group (group B).

The majority of the patients in both, group A (44.4\%) and group B (52.8\%) were in 31 to 40 years age group (Table 1). The mean (SD) age of the participants in group A was 35.7 (7.8) years and in group B was 34.8 (7.7) years. No significant difference of mean age in groups was observed $(\mathrm{p}>0.05)$. 
Table 1: Comparison of Age and Rapid Shallow Breathing Index $(\mathrm{n}=117)$

\begin{tabular}{lcccc}
\hline Age Group & \multicolumn{2}{c}{ Group } & Total & p value \\
\cline { 2 - 3 } & Group A & Group B & & \\
\hline$\leq 30$ & $13(36.1)$ & $10(27.8)$ & $23(31.9)$ & \\
31 to 40 Years & $16(44.4)$ & $19(52.8)$ & $35(48.6)$ & \\
41 to 50 Years & $6(16.7)$ & $5(13.9)$ & $11(15.3)$ & 0.609 \\
$>50$ Years & $1(2.8)$ & $2(5.6)$ & $3(4.2)$ & \\
Mean \pm SD & $35.7 \pm 7.8$ & $34.8 \pm 7.7$ & 0.609 & \\
\hline
\end{tabular}

*Student t-test was done to measure the level of significance

Table 2: Distribution of the patients according to gender $(\mathrm{n}=72)$

\begin{tabular}{lllll}
\hline Gender & \multicolumn{2}{c}{ Group } & Total & p value \\
\cline { 2 - 3 } & Group A & Group B & & \\
\hline Male & $13(36.1)$ & $11(30.6)$ & $24(33.3)$ & 0.617 \\
Female & $23(63.9)$ & $25(69.4)$ & $48(66.7)$ & \\
\hline
\end{tabular}

Chi-square test was done to measure the level of significance

Table 2 is showing the distribution of patients according to gender. In group A and group B female were predominant which was $63.9 \%$ and $69.4 \%$, respectively. Male were $36.1 \%$ and $30.6 \%$ in group A and group B, respectively.

Table 3: Outcome of the patients according to Oswestry disability index (ODI)

\begin{tabular}{lccc}
\hline Disability assess by & \multicolumn{2}{c}{ Group } & p value \\
\cline { 2 - 4 } $\begin{array}{l}\text { Oswestry disability } \\
\text { index (ODI) }\end{array}$ & $\begin{array}{c}\text { Group A } \\
\text { (Mean } \pm \text { SD) }\end{array}$ & $\begin{array}{c}\text { Group B } \\
\text { Mean } \pm \text { SD) }\end{array}$ & \\
\hline Pre treatment & $37.2 \pm 6.4$ & $36.5 \pm 5.8$ & 0.608 \\
2 weeks after treatment & $29.0 \pm 4.5$ & $31.7 \pm 6.0$ & 0.034 \\
4 weeks after treatment & $25.0 \pm 3.5$ & $27.3 \pm 4.5$ & 0.017 \\
8 weeks after treatment & $21.0 \pm 2.7$ & $22.1 \pm 1.6$ & 0.042 \\
\hline
\end{tabular}

Student t-test was done to measure the level of significance

The patient's disability as measured by the Oswestry Disability Index (ODI) is illustrated in Table 3. Before treatment, the mean (SD) ODI score in groups A and B was $37.2(6.4)$ and 36.5 (5.8), respectively and the difference of mean between groups was not statistically significant $(p>0.05)$. After treatment $(2,4$, and 8 weeks) the ODI gradually declined in both groups. A statistically significant difference in mean ODI score in between groups was observed after 2 weeks, 4 weeks, and 8 weeks of treatment $(\mathrm{p}<0.05)$.

Table 4 depicts pain of patients assessed by visual analogue scale (VAS). The mean (SD) score of VAS before treatment was $6.6(0.9)$ and $6.5(0.8)$ in group A and group B respectively; this difference of mean between these two groups was not statistically significant $(p>0.05)$. A statistically significant difference in mean score of VAS in between groups was observed after 2 weeks, 4 weeks, and 8 weeks of treatment $(p<0.05)$. The VAS was decreased gradually in both groups.

Table 3: Outcome of the patients according to Oswestry disability index (ODI)

\begin{tabular}{lccc}
\hline $\begin{array}{l}\text { Assessment by } \\
\text { Visual analogue } \\
\text { scale }\end{array}$ & \multicolumn{2}{c}{ Group } & p value \\
\cline { 2 - 4 } & $\begin{array}{c}\text { Group A } \\
\text { (Mean } \pm \text { SD) }\end{array}$ & $\begin{array}{c}\text { Group B } \\
\text { (Mean } \pm \text { SD) }\end{array}$ & \\
\hline Pre treatment & $6.6 \pm 0.9$ & $6.5 \pm 0.8$ & 0.682 \\
2 weeks after treatment & $4.9 \pm 0.7$ & $5.3 \pm 0.8$ & 0.028 \\
4 weeks after treatment & $3.8 \pm 0.6$ & $4.2 \pm 0.7$ & 0.016 \\
8 weeks after treatment & $2.6 \pm 0.6$ & $2.9 \pm 0.6$ & 0.038 \\
\hline
\end{tabular}

Student t-test was done to measure the level of significance

\section{Discussion}

In a study in the USA it is found that LBP is the most common single musculoskeletal complaint and a major cause for being out of work, resulting in billions of dollars in lost wages and compensations payment annually ${ }^{10}$. So, for various reasons we cannot manage a huge number of disabled patients with low back pain with our present resources and management system. So, the aim of this study is to find out the effects of physiatric modalities regarding the management of the patients with chronic nonspecific low back pain and to make the disabled patients into a working one, so that they can contribute for the prosperity of the persons themselves as well for the nation. Medication and physical therapy including Ultrasound therapy (UST) have proven to be useful adjuncts to an active program of exercise and education that promotes functional restoration.

A total number of 72 nonspecific chronic LBP patients were included for this study of which 36 patients were in treatment group (group A) and the rest 36 patients were in the control group (group B). In both groups female were predominant than male. In group $\mathrm{A}$, female and male were $23(63.9 \%)$ cases and $13(36.1 \%)$ cases respectively. Similarly, female and male were 13 $(36.1 \%)$ cases and $11(30.6 \%)$ cases respectively in group B.

In group A, majority of the patients (44.4\%) were in age group of 31 to 40 years. Similarly in group B, majority of the patients $(52.8 \%)$ were in the age group of $31-40$ years. The mean (SD) age of the patients was 35.7 (7.8) years and 34.8 (7.7) years in group A and group B 
respectively. In present study most of the patients were housewives $(63.9 \%)$ in group A. Similarly in group B, most of the patients were housewives $(61.1 \%)$. The mean (SD) duration of pain was 11.3 (12.5) months and 11.7 (8.7) months in group A and group B respectively.

LBP was dull in most of the cases in both groups which were $23(63.9 \%)$ cases and $20(55.6 \%)$ cases in group A and group B respectively. All of the patients got relieve while resting. Most of the cases in both groups pain was moderate which were $29(80.6 \%)$ and $31(86.1 \%)$ cases in group A and group B respectively. Sedentary life style (58.3\%), repetitive lifting (25.0\%), obesity (19.4\%) and smoking (30.6\%) were the risk factors in group A, Sedentary life style (41.7\%), repetitive lifting (13.9\%), obesity $(13.9 \%)$ and smoking $(23.6 \%)$ were the risk factors in group B. Prolonged sitting (63.9\%), prolonged standing $(66.7 \%)$ and prolonged working $(33.3 \%)$ were the main aggravating factors in group A, similarly prolonged standing $(52.8 \%)$, prolonged sitting (38.9\%) and prolonged working $(38.9 \%)$ were the main aggravating factors in group B. Disability of patient was assessed by Oswestry disability index (ODI).

The mean (SD) score of ODI before treatment were 37.2 (6.4) and 36.5 (5.8) in group A and group B respectively; the difference between these two groups was not statistically significant $(\mathrm{p}>0.05)$. The mean (SD) ODI after 8 weeks of treatment were 21.0 (2.7) and 22.1 (1.6) in group A and group B respectively; the difference between these two groups was statistically significant $(p<0.05)$. In both groups disability was decreased gradually but the improvement was better in group A patients than group B patients, similar result was found in the study of Ebadi et al., (2012) ${ }^{11}$.

Pain of patient was assessed by visual analogue scale (VAS). The mean (SD) score of VAS before treatment were $6.6(0.9)$ and $6.5(0.8)$ in group A and group B respectively; the difference between these two groups was not statistically significant ( $p>0.05$ ). The mean (SD) score of VAS 8 weeks after treatment were $2.6(0.6)$ and 2.9 (0.6) in group A and group B respectively; the difference between these two groups was statistically significant $(\mathrm{p}<0.05)$. In both groups, pain was decreased gradually but the improvement was better in group A patients than group B patients, a similar result was seen in the study of Ebadi et al., (2012)

\section{Conclusion}

The ultrasound therapy could aid in reducing the pain intensity and disability of patients with chronic nonspecific low back pain, effectively. But further multicenter study with a larger sample size is needed to address its benefits to use it routinely and overcome the limitations of this study.

\section{References}

1. Firestein GS, Budd RC, Gabriel SE, McInnes LB, O’Dell JR. Low back pain. In: Kelley's textbook of Rheumatology. 9th ed. Philadelphia, WB Saunders, 2013, pp 665-678.

2. Dixit R. Chapter 47 - Low Back Pain. In: Firestein GS, Budd RC, Gabriel SE, McInnes IB, O'Dell JR, editors. Kelley and Firestein's Textbook of Rheumatology (Tenth Edition) [Internet]. Elsevier; 2017 [cited 2021 Oct 18]. p. 696-716. Available from: https://www.sciencedirect.com/science/article/pii/B97803233169 65000474

3. Waddell G. The back pain revolution. Elsevier Health Sciences; 2004 Mar 1

4. Diamond S, Borenstein D. Chronic low back pain in a working-age adult. Best practice \& research Clinical rheumatology. 2006 Aug 1;20(4):707-20.

5. Duthey B. Background paper 6.24 low back pain. Priority medicines for Europe and the world. Global Burden of Disease (2010),(March). 2013 Mar 15:1-29.

6. Freburger JK, Carey TS, Holmes GM. Physical therapy for chronic low back pain in North Carolina: overuse, underuse, or misuse?. Physical therapy. 2011 Apr 1;91(4):484-95.

7. Grazio S, Markulineiae B, Nemeiae T, Grubisic F, Matijeviae V, Skala H, et al. (2008) Trgovec: Effect of intereferential current and therapeutic ultrasound on lumber spine range of motion in patients with low back pain. In proceedings of the 7th Mediterranean Congress of Physical and Rehabilitation Medicine, Portoro (Slovenia): 18-21.

8. Koes BW, van Tulder M, Lin CW, Macedo LG, McAuley J, Maher C: An updated overview of clinical guidelines for the management of non specific low back pain in primary care. Eur Spine J 2010, 19(12):2075-2094.

9. Hariton E, Locascio JJ. Randomised controlled trials - the gold standard for effectiveness research. BJOG: an international journal of obstetrics and gynaecology. 2018 Dec;125(13):1716.

10. Shakoor MA, Islam MA, Ullah MA, Ahmed MM, Al Hasan S. Clinical profile of the patients with chronic low back pain-A study of 102 cases. Journal of Chittagong Medical College Teachers' Association. 2007;18(2):16-20.

11. Ebadi S, Ansari NN, Naghdi S, Jalaei S, Sadat M, Bagheri H, Vantulder MW, Henschke N, Fallah E. The effect of continuous ultrasound on chronic non-specific low back pain: a single blind placebo-controlled randomized trial. BMC musculoskeletal disorders. 2012 Dec;13(1):1-0. 